\title{
Identification and Evaluation of Data Sources for the Commercial Buildings Retrofit Market
}
S. A. Smith
D. R. Johnson

October 1986

Prepared for the U.S. Department of Energy under Contract DE-AC06-76RLO 1830

Pacific Northwest Laboratory Operated for the U.S. Department of Energy by Battelle Memorial Institute 


\title{
DISCLAIMER
}

This report was prepared as an account of work sponsored by an agency of the United States Government. Neither the United States Government nor any agency thereof, nor any of their employees, makes any warranty, express or implied, or assumes any legal liability or responsibility for the accuracy, completeness, or usefulness of any information, apparatus, product, or process disclosed, or represents that its use would not infringe privately owned rights. Reference herein to any specific commercial product, process, or service by trade name, trademark, manufacturer, or otherwise, does not necessarily constitute or imply its endorsement, recommendation, or favoring by the United States Government or any agency thereof. The views and opinions of authors expressed herein do not necessarily state or reflect those of the United States Government or any agency thereof.

\author{
PACIFIC NORTHWEST LABORATORY \\ operated by \\ BATTELLE \\ for the \\ UNITED STATES DEPARTMENT OF ENERGY \\ under Contract DE-AC06-76RLO 1830
}

Printed in the United States of America

Available from

National Technical Information Service

United States Department of Commerce

5285 Port Royal Road

Springfield, Virginia 22151

NTIS Price Codes

Microfiche A01

Printed Copy

$\begin{array}{ll}\text { Pages } & \text { Price } \\ \text { Podes }\end{array}$

001-025 A02

026-050 A03

051-075 A04

076-100 A05

101-125 A06

126-150 A07

151-175 A08

176-200 A09

201-225 A010

226-250 A011

251-275 A012

276-300 A013 
PNL -6015

UC-95d

IDENTIFICATION AND EVALUATION

OF DATA SOURCES FOR THE

COMMERCIAL BUILDINGS RETROFIT

MARKET

S. A. Smith

0 . R. Johnson

October 1986

Prepared for

the U.S. Department of Energy

under Contract DE-AC06-76RLO 1830

Pacific Northwest Laboratory

Richland, Washington 99352 


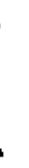




\section{SUMMARY}

The objectives of this study are to identify data sources that provide information on current and future levels of commercial buildings retrofit activity in the U.S., and to evaluate the coverage these data sources provide the commercial retrofit industry. Data sources evaluated include reports, magazines, computerized data bases, and surveys.

Relevant data sources were identified through a literature review and by telephone and mail contacts with building industry experts and trade associations. A brief summary of each of the data sources is provided and recommendations are made for gathering additional data to supplement the existing data source.

Based on this evaluation of various data sources for the comercial building retrofit market, four data sources appear to be valuable:

- Dodge/DRI Construction Analysis System and Dodge/ORI Building Stock Data Base and Forecast. These two sources represent the most complete and detailed information available. The Construction Analys is System provides the best indication of current and historical information on the level and location of retrofit activity. The Building Stock Data Base is most useful for characterizing the potential market for such activities. Although this data base is the most comprehensive in terms of providing information on the comercial retrofit market, it does not categorize commercial building retrofit activity by distinct building technologies such as boiler system, exterior appearance, etc.

- The Complete Renovation Fact Book. This resource can be used to provide supporting data to the Dodge/ORI sources. While the survey covers only subscribers to the publication, some additional information can be useful.

- Yankelovich, Skelly and White's Building Owner Viewpoint Study. Although this is a proprietary study that cannot be used in published 
reports, it provides insight and information on decision makers, motivations, levels of activity and other factors that are not available elsewhere.

- F.W. Dodge Reports. Dodge "Item" Keports identify individual systems affected for single systems alteration projects. Dodge Reports provide a descriptive summary with statistical information for all major alteration projects. This information includes the names, addresses, and telephone numbers of architects, owners, and contractors, which may be used to obtain more detailed follow-up information. Dodge/Scan item films are also availabie. 


\subsection{INTRODUCTION}

The recent growth in the market for retrofitting, refurbishing, remodeling and altering commercial building space has been spurred by several factors: limited expansion area in metropolitan regions, desire for prime locations with modern facilities, municipal and cjvic incentives for renewal of downtown areas, and federal tax credits that favor the adaptive reuse of older buildings.

The emergence of commercial retrofit as a significant market presents unique opportunities for energy conservation. Retrofit activity greatly differs from new buildings in motivation, planning, design and construction. Since the designer and contractor must work with a given set of structural and aesthetic constraints that are not easily changed, the challenges involved in this kind of construction can be more complex than new construction, where theoretically all variables can be changed.

Currently, the factors that characterize the size and dynamics of this retrofit market are not as well understood as factors for new construction. Information is needed on the size of the retrofit market and the level of retrofit activity to determine its energy conservation potential. This information will assist in resource allocation decisions for research and technology transfer efforts. To effectively transfer research results that would enable building industry segments to exploit the conservation potential in the retrofit market, some understanding of how many and which firms are engaged in this business is needed.

\subsection{OBJECTIVE}

The objective of this report is to identify and evaluate the data sources that provide information on the current and future levels of commercial building retrofit activity in the United States. These sources are evaluated on the basis of their coverage of the commercial retrofit market, the quality and 
reliability of their data and its the overall usefulness for characterizing the market, given the objective of transferring energy conservation technologies to market practitioners.

\subsection{SCOPE}

Data sources examined in this report included published reports and data bases available from public and private institutions. The following information was requested for each data source identified:

- Title of Data Source - The name of tlee report, survey or data source.

- Name of Firm - The agency, firm or institution generating the data source.

- Contact Persons - Persons in the firm or institution responsible for the sale or distribution of the data, and persons responsible for generating the data.

- Medium - The form in which the data is distributed (i.e., computer tape, newsletter, custom published report, ezc.)

- Availability and Accessibility of Data Source - How the information in the data source can be accessed, and ary limitations or conditions on the use of the data.

- Cost of Access to Information - The fee or price of purchasing the information.

- Retrofit Morphology/Nomenclature and Definitions - The classification system used in organizing the data. This is important because different industry groups use different terms and characteristics to subdivide or otherwise characterize the retrofit market. The way terms are defined may have a major effect on what kinds of activities are described by the data.

- Commercial Retrofit Coverage - The extent of coverage of the data source, including areas other than comercial retrofit that are covered. Parameters describing coverage are as follows: 
- Geographic--how much of the U.S. is described, and what areas are described in detail

- Iime frame/series--time period covered by the data source, and for what time periods are data provided

- Building type--the types of commercial buildings covered, and how the categories are determined

- Criteria for inclusion--factors used to decide how to account for building activity included in the data source

- Data excluded from source--any commercial building activity not described in the data source.

- Primary Data Sources - The source of the primary data used to make forecasts or estimates.

- Primary Data Collection Methodology - How the primary data are collected.

- Primary Data Manipulation Methodology - The models, algorithms, sampling methods or other means employed to modify raw primary data.

- Frequency of Updates - How often the primary data are collected, and how often the final output is modified.

- Level of Aggregation - The level of aggregation at which the primary data are modified.

\subsection{METHODOLOGY}

Data sources were identified by conducting a brief literature search, and by contacting public agencies, trade and professional associations in the building industry, and firms that track the construction industry. These contacts were used to generate information about available data, and this information was used to characterize each data source in both descriptive and evaluative terms.

The evaluation was based on the data quality, comprehensiveness of coverage, and the methodology used. Although information was obtained on the cost 
of acquiring or accessing the data sources, the evaluation was not based on the basis of cost/benefit. Rather, those data sources most useful in accurately and comprehensively characterizing the retrofit market were given the highest ratings. 


\subsection{COMMERCIAL RETROFIT DATA AND INFORMATION SOURCE DESCRIPTIONS}

This section describes each of the data sources identified in this study. The descriptions are based on the various parameters listed in Section 1.2. Information on each of the parameters was not available for all sources; where infomation was not provided, the parameter was left blank. In these instances the firm providing the data source should be contacted directly for more information.

\subsection{CONSTRUCTION ANAL YSIS SYSTEM (CAS)}

Firm

McGraw-Hill, Inc.-Dodge/DRI Construction and Real Estate Information Service

24 Hartwell Ave.

Lexington, MA 02173

\section{Contacts}

Bernard Paque--Manager and principal contact (617) 863-5100

Rick Gold--Methodo?ogy (617) 863-5100

Nicholas 0. Rockler (outside consultant)--Methodology (617) 863-5100. Medium Type

On-line computer data base, hard copy, diskette, magnetic tape, CD-ROM, etc.

Availability and Accessibility of Data Source

Access is through DRI's time-shared computer network, using English language menu-driven software. The Department of Energy, through the Energy Information Agency, is already a subscriber to Dodge/ORI data services through a basic ordering agreement. Assuming this agreement is renewed, other DDE entities (including laboratories) could participate in the basic ordering agreement.

Cost of Access to Information

$\$ 36,000$ annual subscription fee to the service. 
Retrofit Morphology/Nomenclature and Definitions

This sort capability of the data base includes the following descriptive parameters:

- new construction

- additions to existing structures

- alterations to existing structures.

\section{Commercial Retrofit Coverage}

Concepts

Square footage, dollar value, number of buildings, ownership class (public or private).

Geographic

County level data for entire U.S.

Time Frame/Series

1967 to present.

Building Type

209 structure types. In addition, 59 categories of commercial buildings are classified under the following major divisions:

- store and restaurants

- warehouses (nonmanufacturer owned)

- office and bank building

- parking garages and auto service

- schools and colleges

- laboratories (nonmanufacturer owned)

- libraries and museums

- government service buildings

- religious buildings

- amusement, social and recreational buildings

- miscellaneous nonresidential. 
Criteria for Inclusion

$\$ 50,000$ or larger construction projects (effective March 1986; prior limit was $\$ 25,000)$.

Data Excluded from Source

One and two family housing.

\section{Other Features}

Forecasts, statistical analyses, reports, and graphics can be generated using software packages on-line. This software system, known as EPS, provides prompted capability for:

- calculations

- seasonar adjustments

- full service plottings

- graphic display options

- custon report writing

- correlation analyses

- least square regression analyses

- advanced regression analyses.

Primary Data Sources

1. Dodge/DRI Construction Analysis System (CAS) Data Base

2. ORI Regional/County Economic and Demographic Data Base

3. F. W. Dodge Reports.

Primary Data Collection Methodology

Data on building plans, bids and starts are collected by the $F$. W. Dodge Division of McGraw-Hill Information Systems Company on a daily census basis, covering all U.S. counties.

Primary Data Manipulation Methodology

Users can manipulate the data base according to their own needs (see above), or can arrange for special consulting services.

Frequency of Updates

Monthiy. 
Level of Aggregation

County, major SMSA, regional (9 regions) and national levels of aggregation are available. User-defined aggregation is also available.

\subsection{CONSTRUCTION MARKET FORECASTING SERVICE}

$\underline{\text { Firm }}$

McGraw-Hill, Inc.-Dodge/ORI Construction and Real Estate Information Service

24 Hartwell Avenue

Lexington, MA 02173

Contacts

Bernard Paque (617) 863-5100

Rick Gold (617) 863-5100

Steve L'Heureux (617) 863-5100

Medium

- Paper studies (four deliverables of the CMFS Review)

- On-line access to data and models used in the market analysis

- Output via diskette or magnetic tape upon raquest (additional fee).

Availability and Accessibility of Data Source

Both the paper studies and the on-line seryice are available on a

subscription basis.

Cost of Access to Information

$\$ 10,875$ annual subscription fee to the service.

Retrofit Morphology/Nomenclature and Definitions

Concepts

The service is intended to provide market information for building products manufacturers and distributors. Demographic characteristics, business composition, economic conditions and outlook, labor force statistics, and information on the demand and supply for various building types is provided.

Geographic

National and nine census regions analysis. 
Time Frame/Series

Annual from 1970 with projections for 5 out-years.

Quarteriy frequency.

Building Type

Structure types included are presented in the attachments.

Criteria for Inclusion

Same as CAS (Section 2.1).

Data Excluded from Source

Same as CAS (Section 2.1).

Primary Data Sources

Dodge/DRI CAS data base. Locational factors such as labor availability and quality, wages, tax burden, housing costs, and proximity to markets are used to determine demand for locating businesses and residences in an MSA.

- ORI Regional Information Service. See the attachments.

- DRI U.S. Economic Service. See the attachments.

Primary Data Collection Methodology

See CAS.

Primary Data Manipulation Methodology

Statistical techniques and a comprehensive system of national, regional, and local economic forecasts.

Frequency of Updates

Four times per year.

Level of Aggregation

Nine Census Bureau regions. 


\subsection{REAL ESTATE AND PLANNING SERVICE (REAPS)}

Firm

McGraw-Hil1, Inc.-Dodge/DRI Construction and Real Estate

Information Service

24 Hartwell Avenue

Lexington, MA 02173.

\section{Contacts}

Bernard A. Paque (617) 863-5100

Rick Gold (617) 863-5100.

Medium

- paper studies (two deliverables of the REAPS review)

- on-line access to data and models used in the market analyses

- output via diskette or magnetic tape upon request.

Availability and Accessibility of Data Source

Both the paper studies and the on-line service are available on a subscription basis.

Cost of Access to Information

- \$14K annual subscription fee to the service

Retrofit Morphology/Nomenclature and Definitions

\section{Concepts}

The service is intended to provide market information for building products manufacturers and distributors. Demographic, business composition, economic conditions and outlook, labor force statistics, and information on the demand and supply for various butiding types are provided.

Geographic

Top 50 U.S. metropolitan markets, with limited analysis of the next 150 cities.

Time Frame/Series

Annual from 1970 with projections for five out-years. 
Building Type

Six structure types are included in the analysis:

- office buildings

- hotels and motels

- commercial warehouses

- retail establishments

- multi-family housing

- single family housing.

Criteria for Inciusion

Same as CAS.

Data Excluded from Source

Same as CAS.

Primary Data Sources

Dodge/DRI CAS data base. Locational factors such as labor availability and quality, wages, tax burden, housing costs and proximity to markets are used to determine demand for locating businesses and residences in a MSA.

Primary Data Collection Methodology

See CAS.

Primary Data Manipulation Methodology

Statistical techniques and a comprehensive system of national, regional and local economic forecasts.

Frequency of Updates

Two times per year.

Level of Aggregation

Individual metropolitan statistical areas. 


\subsection{BUILDING STOCK DATA BASE AND FORECAST}

Firm

McGraw-Hi11, Inc.-Dodge/DRI Construction and Real Estate Information Service

24 Hartwel? Avenue

Lexington, MA 02173.

Contacts

Bernard Paque (617) 863-5100

Nicholas Rockler (617) 863-5100

Medium Type

- printed report (standard)

- customized reports on request

- on-line data base

- subsets of the data base on diskettes for microcomputers are available at extra cost.

Availability and Accessibility of Data Source

The data base is available on-line for access at the client's convenience. Reports are generated on an order basis.

Cost of Access to Information

Retrofit Morphology/Nomenclature and Definttions

- total standing stock

- yearly completion (net).

Commercial Retrofit Coverage

Concepts

The primary purpose of this data base is to track the existing stock of buildings by type, location and construction year. The construction year information is extremely useful in assessing the potential market for retrofit activities, assuming that the need for, (and likelihood of,) retrofitting a building is a function of building age. 
Geographic

National coverage by county.

Time Frame/Series

Quarterly time series by county are available on floorstock for all building types. National estimates prior to 1970 are available for selected structure types.

\section{Building Type}

Benchmark estimates were made for 35 structure types, then aggregated to 15 structure groups as listed below:

\begin{tabular}{|c|c|}
\hline Nonresidential & Residential \\
\hline \multirow{3}{*}{$\begin{array}{l}\text { Retail Stores and Restaurants } \\
\text { Automobile Service and Parking Garages } \\
\text { Offices }\end{array}$} & Single Family Houses \\
\hline & Multi-Family \\
\hline & Hotel/Motel \\
\hline Manufacturing Plants & Dormitories \\
\hline Commercial and Manufacturing Warehouses & \\
\hline Educational Buildings & \\
\hline Government Buildings & \\
\hline Religious Buildings & \\
\hline Hospitals and Health Care & \\
\hline Amusement, Social/Recreational & \\
\hline Miscellaneous & \\
\hline
\end{tabular}

Criteria for Inclusion

Al] residential and nonresidential structures.

Data Excluded from Source

Geographic and structure type detail for nonresidential building stock. While dollar-value national estimates are available for nonresidential buildings, efforts to translate these values into physical characteristics were unsuccessful. 
Primary Data Sources

For benchmark estimates of floorstock:

- County Business Patterns

- Bureau of the Census (population and industry specific surveys)

- General Services Administration Surveys

- National Center for Educational Statistics Data

- National Center for Health Statistics Data

- Nonresidential Buitdings Energy Consumption Surveys I and II For additions to floorstock:

- Construction Analys is System Data base

- U.S. Department of Commerce estimates of value of construction put in place.

Primary Data Collection Methodology

The diverse sources listed above were used to estabiish a benchmark estimate of floorstock by justifying the differences in the data to make a coherent estimate. Empirical evidence based on surveys that produced county leve? data were used for the following categories: single family dwellings, multi-family dwellings, federally occupied structures, higher education buildings, warehouse space and retail selling space.

Estimates for other building types were based on proxy measurements. Space requirements for items such as hospital beds, numbers of employees or students, etc., were used in combination with known statistics on these proxies as one method. Another method was to use state or national sample estimates and distributions for these proxies.

Additions to floorstock are collected through the Dodge/DR! Construction Analysis System, which collects data on building permits in local building code jurisdictions.

Primary Data Manipulation Methodology

The benchmark estimate is the starting point, and is addeo to annually as information is collected on building permits. A decay function is employed to 
estimate demolitions for each building type. For single-family dwellings, four-region removal rates were determined from the decennial census data.

Forecasts of floorstock are generated using the macro and regional economic models provided by the Dodge/DRI Construction Market Forecasting Service (CMFS). Variables that drive the economic models include forecasts of employment, economic consumption, population growth, and financial variables such as interest rates. Forecasts are available on national and regional levels for nine regions. The regional forecasts are then distributed to a county level for each building type using long-run and short-run county historical average shares of floorstock. This method does not account for unique county circumstances, but is sensitive to the long term economic importance of each county. The breakdown of structure types available in the forecast are as follows:

- Nonresidential Buildings:

- Commercial and Manufacturing Stores

- Commercial and Manufacturing Warehouses

- Offices and Bank Buildings

- Parking Garages and Service Stations

- Manufacturing

- Institutional:

- Education

- Health

- Public

- Religious

- Amusement

- Miscellaneous

- Residential:

- Housekeeping

- Single Family

- Mutti-Family

- Nonhousekeeping:

- Hotels and Dormitories. 
Frequency of Updates

Annually.

Level of Aggregation

Multiple aggregation levels are available.

\subsection{SPECIFYING ENGINEER MAGAZINE}

Firm

Cahner's Publishing Company

275 Washington St.

Newton, MA 02158-1630.

Contacts

Elizabeth Baatz (617) $964-3030 \times 368$

Mark Gup (312) 635-8800 x273

Kermit Baker (617) $964-3030 \times 497$.

Medium

Activity levels published annually in Specifying Engineer.

Availability and Accessibility of Data Source

Data available through subscription to Specifying Engineer. Topical reports could be performed on a contract basis.

Cost of Access to Information

Retrofit Morphology/Nomenclature and Definitions

Commercial Retrofit Coverage

Geographic

National level and four region level.

Time Frame/Series

Building Type

Criteria for Inclusion

Data Excluded from Source 
Primary Data Sources

Based on U.S. Department of Cormerce Data.

Primary Data Collection Methodology

No primary data was collected.

Primary Data Manipulation Methodolagy

A benchmark estimate was established for 1977 using U.S. Department of Commerce data. This data is updated annually using econometric models.

Frequency of Updates

Annual.

Level of Aggregation

National and four regional.

2.6 CONSTRUCTION REVIEW (PUBLICATION)

Firm

U.S. Department of Commerce, International Trade Administration.

Contacts

Patrick H. MacAuley, Construction Industry Economist (202) 377-0132.

Medium

Government publication.

Availability and Accessibility of Data Source

Available from U.S. Government Printing Office on a subscription basis. Retrofit Morphology/Nomenclature and Definitions

Additions and alterations are reported in the aggregate, but separately from new construction for residential construction. For nonresidential construction, additions and alterations are reported together with new construction. 
Commercial Retrofit Coverage

\section{Concepts}

This publication covers the entire construction industry, including nonbuilding construction. Statistics on the value of contracts put in place, disaggregated by residential, various sorts of nonresidential and other categories are given. Each issue provides an updated analysis of trends in the construction industry. One table, Table $0-3$, includes renovations with additions and new construction. The statistics in this table are derived from Dodge data, not from census data. If the Dodge data can be justified with census data, the value of renovation contracts could be derived, but is not specifically provided.

Geographic

Summaries are provided for national, state and some selected SMSA levels. Time Frame/Series

Monthily for the past two years, annual for the five years prior to that. Building Type

The following building types are included in the statistical summaries:

\begin{tabular}{|c|c|}
\hline Nonresidential & Residential \\
\hline industriat & 1 unit structures \\
\hline office buildings & 2 or more units \\
\hline other commercial & nonhousekeeping \\
\hline religious & \\
\hline educational & \\
\hline hospital and institutional & \\
\hline miscellaneous & \\
\hline farm & \\
\hline
\end{tabular}

Criteria for Inclusion

Data Excluded from Source 


\section{Primary Data Sources}

Bureau of Census computer tapes of building permits reported by all U.S. building code jurisdictions.

Primary Data Collection Methodology

Reports by local building code jurisdictions to the Census Bureau are based on responses to a mail survey of 8,300 locations out of the approximately 17,000 building code jurisdictions that issue building permits. However, this survey excludes renovations, although it does include additions to existing structures.

Limitations to Primary Data Collection Methodology

1. Sampling errors.

2. Some construction work in building permit jurisdictions escapes recording.

3. Definitional difficulties.

4. Inability or unwillingness of respondents to provide correct information.

5. Inability to obtain information about all cases in the sample.

6. Data processing errors.

Primary Data Manipulation Methodology

Statistical sumary of raw data on Census Bureau's tapes of reported building permits.

Limitations to Data Manipulation Methodology

Frequency of Updates

Monthly.

Level of Aggregation

National, state and some selected SMSAs. 


\subsection{THE COMPLETE RENOVATION FACT BOOK}

Firm

QR Publishing, Inc.

8 S. Michigan Ave.

Chicago, IL 60603

Contacts

Bill Murray, Marketing (312) 922-5402

Lynn McMillan, Communications (312) 922-5402.

Medium

Printed study.

Availability and Accessibility of Data Source

Purchase.

Cost of Access to Information

$\$ 150.00$ per copy.

Retrofit Morphology/Nomenclature and Definitions

Additions to existing buildings and remodeling are classified as renovations, and are counted together.

Commercial Retrofit Coverage

\section{Concepts}

Tracks size and scope of comercial renovation market/potential. Includes inventory of structures by type, region, year constructed, and number of floors.

Geographic

National and the four Census Bureau regions.

Time Frame/Series

Annual study.

Building Type

All but single-family residential are included. 
Criteria for Inclusion

Data Excluded from Source

Single-family residential buildings are excluded from the study.

Primary Data Sources

Information is gathered from a survey conducted by Commercial Renovation magazine.

Primary Data Collection Methodology

Survey.

Frequency of Updates

Annual.

Level of Aggregation

\subsection{BUILDING OWNER VIEWPOINT STUDY}

Firm

Yankelovich, Skelly and White, Inc.

369 High Ridge Road

Stanford, CT 06905

or

575 Madison Avenue

New York, NY 10022.

Contacts

Ardith Rivel (203) 322-7600

Jane Bovich (203) 322-7600.

Medium

Paper Study.

Availability and Accessibility of Data Source

THIS IS A PROPRIETARY STUDY AND MAY NOT BE USED FOR PUBLICATION OR

DISSEMINATION IN ANY WAY WITHOUT THE EXPRESS WRITTEN CONSENT OF YSW AND THEIR OTHER SPONSORS.

Subscription as sponsor of a multi-client study. 
Cost of Access to Information

Generalized sponsorship $=\$ 5,800$ if subscription is in before study starts.

Generalized sponsorship $=\$ 6,800$ if subscription is in after study starts. Company-specific sponsorship $=\$ 10,800$ (this entitles the subscriber to insert custom-designed questions into the survey that forms the basis of the study).

Retrofit Morphology/Nomenclature and Definitions

Renovation is defined as "exterior or internal structural changes, major systems and/or equipment upgrading or major changes in the exterior or interior appearance of the building" involving $\$ 50 \mathrm{~K}$ or more.

Replacement is defined as "replacing old, worn, or inefficient products and equipment with new items" involving \$25K or more.

Commercial Retrofit Coverage

\section{Concepts}

This study is a multi-sponsored nation-wide project to be conducted among a representative sample of building owners and managers of existing commercial buildings. The study will define the nature and scope of the renovation and replacement markets for products used in these buildings and assess how to reach effectively those who own and manage these properties. This research will determine:

- Marketing Data:

- who initiates and ultimately makes the decision to renovate and replace

- why and under what circumstances these activities are undertaken

- to whom building owners and managers turn for renovation and replacement advice 
- the size of the renovation and replacement markets

- how these markets segment according to size, age and type of building, size of metropolitan area, and geographic region.

- Product Purchasing Patterns:

- the communications and media environment

- company-specific information.

Geographic

Nationa 1 .

Time Frame/Series

Single "snapshot."

Building Type

The following building types are defined:

- educational institutions (public, private; primary, secondary)

- hospitality (hotels, motels and restaurants)

- health care facilities (hospitals and nursing homes)

- office buildings (single and multi-client)

- retail services (chains and major independents).

Criteria for Inclusion

Buildings of $50 \mathrm{~K}$ sq ft or more, renovation projects of $\$ 50 \mathrm{~K}$ or more, replacement projects of $\$ 25 K$ or more, and large organizations (the definition of "large" varies by building type:

- "educational" designation is based on number of students

- "health care" category is based on number of beds, or a combination of dollar volume and number of employees

- hospitality and retail services are based on dollar volume

- office buildings are based on dollar volume or number of employees

- data excluded from source. 
Primary Data Sources

The study is based on 1100 interviews with building owners, managers or equivalent decision makers. These respondents will have been screened by telephone.

Other sampling procedures are implemented to insure that the 5 building types are equally covered.

Primary Data Collection Methodology

Face-to-face interview survey.

Primary Data Manipulation Methodology

Correlations, regressions and other statistical methods.

Frequency of Updates

This is a one-time study.

Level of Aggregation

Nationa? level and four region levels. 


\subsection{ASSESSMENT}

The most comprehensive data available are from the combined services and multiple products of Dodge/ORI. They characterize the commercial retrofit market as "AAMR," or Addition Alteration, Repair and Maintenance. This category was originally developed as a part of a multi-client study that supported the development of the building stocks data base, where the data for retrofits are now kept and updated.

The Dodge/DRI data are the only comprehensive data for both existing buildings floorstocks, which is useful in determining the potential market, and for the level of construction contract activity, an indication of current and projected market for energy conserving technologies. These data are based on data from Dodge Reports collected by the F. W. Dodge Division of McGraw-Hill Information Systems Company.

However, the Dodge/DRI data do not appear to be useful for characterizing the kinds of retrofit activities as they relate to distinct building technologies. For example, the data base cannot be sorted according to whether the retrofit contract was primarily for a boiler systen, for exterior appearance, for energy efficiency or for a building function change that involves electrical, plumbing, HVAC and interior finishes.

The YSW study may contain statistically valid indicators of the reasons for deciding to retrofit. These reasons may provide answers to the relative levels of emphasis on types of equipment and design considerations that motivate retrofit activity.

One way to develop profiles of typical jobs and estimate market shares of the different kinds of retrofit activities would be to look at the projects on file with Dodge under their Dodge Reports title. Dodge reports keep detailed plans and blueprints on each construction job in the country that has been permitted. By examining a large enough sample of projects from these files, some sense can be gained of the types of equipment and design services specified by typical jobs, and what percentage of the activity is accounted for by each job type. 
This would be useful in answering many questions. Industry experts state that the retrofit market now serves mainly buildings built in the 1930s, 1940s, and 1950s. These experts also note that the number of existing buildings of this vintage is dwindling. The next generation of retrofit activities will apply to the next historical generation of buildings--built in the 1960s and 1970s--and that this new generation of buildings will require sophistication beyond the current state of the art.

The best morphology for this would be:

- Additions

- Alterations

- Major Replacement

- Renovation

- Rehabilitation

- Historic Renovation.

This could be further developed according to the building systems typically involved.

The best way to obtain additional information and insight into the current composition and future direction of the retrofit activity would be to buy into the Dodge/DRI data and to contract with them for some special studies. These studies should identify the typical projects and the design and equipment included in those projects. A market share for the typical projects could be developed based on a detailed analysis of a sample of projects. The other important parameter to include is the vintage of the existing buildings being retrofitted as well as the particular building type. This should be compared with the existing stock to see what the size of the remaining market is by vintage. This will indicate the types of technical R\&D projects that will be needed to provide future capability.

However, it should be noted that none of the data will ever be perfect since it is based on permit data sampled from over 17,000 building code jurisdictions. Some information does not get reported, and projects are handled in very different ways by local jurisdictions. Also, the sampling procedures may bias the data somewhat. 


\section{DISTRIBUTION}

No. of

Copies

OFFSITE

10 Ernie Freeman

Department of Energy

Forrestal Building

1000 Independence Avenue

Washington, D.C. 20585

30 DOE Technical Information

\section{ONSITE}

DOE Richland Operations office

J. J. Sutey/D, R. Segna

31 Pacific Northwest Laboratory

B. L. Mohler

T. J. Secrest (10)

S. A. Smith (10)

Economics Library (3)

Publishing Coordination (2)

Technical Information (5) 


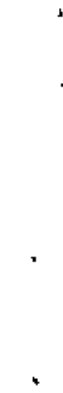

